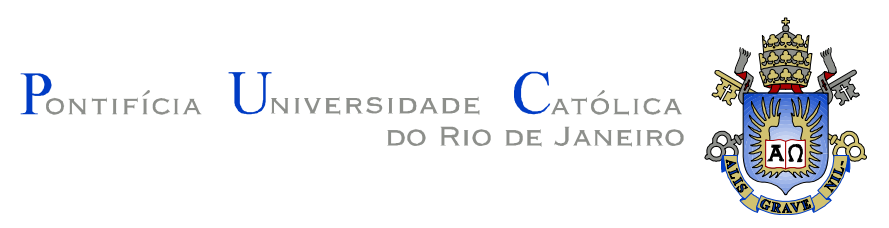

Débora Kfuri Regal

\title{
Getúlio Vargas volta ao Catete: \\ A estratégia de propaganda varguista nas eleições de 1950
}

\section{Dissertação de Mestrado}

Dissertação apresentada como requisito parcial para obtenção do grau de Mestre pelo Programa de PósGraduação em História Social da Cultura, do Departamento de História da PUC-Rio.

Orientador: Prof. Luís Reznik

Rio de Janeiro

Setembro de 2007 


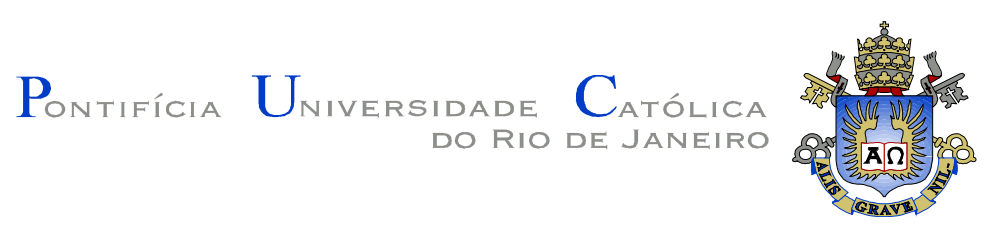

Débora Kfuri Regal

\title{
Getúlio Vargas volta ao Catete: a estratégia de propaganda varguista nas eleições de 1950
}

Dissertação apresentada como requisito parcial para obtenção do grau de Mestre pelo Programa de Pós-Graduação em História Social da Cultura do Departamento de História do Centro de Ciências Sociais da PUC-Rio. Aprovada pela Comissão Examinadora abaixo assinada.

\author{
Profo Luís Reznik \\ Orientador \\ Departamento de História \\ PUC-Rio
}
Profª. Maria Celina Soares D’Araujo CPDOC Fundação Getúlio Vargas

Profo Nelson Rojas de Carvalho Departamento de Ciência Política

UFRRJ

Profo João Pontes Nogueira

Vice-Decano de Pós-Graduação do Centro de Ciências Sociais

PUC-Rio

Rio de Janeiro, 03 de setembro de 2007. 
Todos os direitos reservados. É proibida a reprodução total ou parcial do trabalho sem autorização do autor, do orientador e da universidade.

Débora Kfuri Regal

Cursou graduação em Comunicação Social, com habilitação em Jornalismo, pelo Centro Universitário da Cidade (2004); e pós-graduação lato senso em História do Brasil pela Universidade Cândido Mendes (2007). Como jornalista trabalhou na TV Globo, Globonews, e no departamento de marketing do Laboratório Sérgio Franco. Atualmente trabalha no curso de Licenciatura em História, modalidade educação a distância, da PUCRio e realiza estudos na área de História, com ênfase em História do Brasil Republicano.

Ficha Catalográfica

Regal, Débora Kfuri

Getúlio Vargas volta ao Catete: a estratégia de propaganda varguista nas eleições de 1950 / Débora Kfuri Regal; orientador: Luís Reznik. - 2007.

115 f. : il. ; $30 \mathrm{~cm}$

Dissertação (Mestrado em História)-Pontifícia Universidade Católica do Rio de Janeiro, Rio de Janeiro, 2007.

Inclui bibliografia

1. História - Teses. 2. História social da cultura. 3. Vargas, Getúlio, 1883-1954. 4. Eleições presidenciais. 5. Propaganda política. I. Reznik, Luís. II. Pontifícia Universidade Católica do Rio de Janeiro. Departamento de História. III. Título.

CDD: 900 


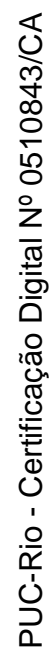

Para Guilherme, meu amor. 


\section{Agradecimentos}

Ao meu orientador, Luís Reznik, pela paciência incansável, pela disponibilidade, pelo incentivo, e pela serenidade com que conduziu essa pesquisa. $\mathrm{Me}$ guiando pelos caminhos da História, Luís me proporcionou aprendizados preciosos para a vida. A ele agradeço também a oportunidade de participar do curso de Licenciatura em História, modalidade a distância, parceria entre PUC-Rio e UERJ, onde tenho a possibilidade de expandir minha caminhada apaixonada pela história, interagindo com situações e pessoas tão fascinantes quanto inesperadas para mim.

À professora Margarida de Souza Neves pelo carinho, pela prazerosa convivência, e sobretudo por me dar a oportunidade de errar. Poder corrigir um erro é sempre um presente, pois aprendemos duplamente: com os acertos e com as correções. Guida me abriu caminhos e, assim como Luís, me deixa ensinamentos que vou levar para a vida toda.

Às minhas famílias: a Kfuri, a Rezende, a Resende Valle, e a Regal. Em especial destaco algumas pessoas: minha mãe, pela paciência e pela torcida; minha irmã, Regina Kfuri, pela revisão atenta - na dissertação e na vida; Ricardo, pelo incentivo e pelos conselhos; meu sogrão, pelo interesse, pelo carinho e por sempre me ajudar espontaneamente nas pesquisas; minha sogra, pelo interesse e pelo carinho; vó Dalva pelas maravilhosas histórias que a memória conseguiu guardar; e Maria Clara, que me ensina tanto a cada dia, por não reclamar muito das minhas ausências e sempre me receber de volta com aquele sorrisão!

À Maria Celina Tavares Carneiro, pelas inimagináveis trocas entre a Engenharia e a História, e pela amizade de tantos anos, que se reinventa a cada dia.

Às amizades que nasceram e cresceram no "infortúnio": Vanessa, Teca, Eliane, Gabriel, Marise, Marcus, João Pedro e Jurema, por tornarem minha jornada (e minha vida!) muito mais divertida e confiante.

Aos colegas HD, em especial Ilmar, Cláudio e Maisa, pelo carinho, pelo estímulo, pelos conselhos, pela bibliografia, e por serem exemplos. Especialmente ao Cláudio, por fazer meu trabalho enquanto eu escrevia...

Aos professores Nelson Rojas de Carvalho e Marcelo Gantus Jasmin, que foram muito importantes na fase de qualificação do projeto e contribuíram muito para 
a organização desta pesquisa. E à Maria Celina D’Araújo, por participar da banca de dissertação, e também pelas suas contribuições através de seus textos.

À Edna, Anair, Cleusa, e Moisés, pelos cafés, por quebrarem todos os galhos e por fazerem deste departamento um lugar tão agradável. E também ao pessoal da biblioteca da PUC e da sala de consulta do CPDOC, que sempre foram muito atenciosos.

À Maria Cristina Leôncio dos Santos, por manter minha vida sempre em ordem e funcionando. E à Elanir Lopes Barreto, por manter minha cabeça em ordem e funcionando, por algum tempo.

Ao Ricardo Medina e à Flávia Souto, por me darem o "start" para essa pesquisa.

À CAPES, ao CNPQ, e à PUC-Rio por viabilizarem a realização deste trabalho.

À Glória e Lirian Kfuri, por estarem sempre comigo e por me deixarem a História como herança.

E a Guilherme de Rezende Regal, meu amor, pela coragem, pela confiança, pela motivação, por estar sempre comigo e por fazer a minha vida ser perfeita todos os dias. 


\section{Resumo}

Regal, Débora Kfuri; Reznik, Luís. Getulio Vargas volta ao Catete: a estratégia de propaganda varguista nas eleições de 1950. Rio de Janeiro: 2007. 115 p. Dissertação de Mestrado - Departamento de História, Pontifícia Universidade Católica do Rio de Janeiro.

O objetivo deste trabalho é acompanhar as etapas da campanha de Getúlio Vargas às eleições presidenciais de 1950. Tendo chegado à presidência duas vezes através de golpes de Estado e uma vez por voto indireto, Vargas voltaria ao poder através do voto popular, graças a uma campanha inteligente e moderna. Em menos de dois meses, sua comitiva visitou todas as capitais do país, o Distrito Federal, e mais de 50 cidades, estabelecendo uma comunicação direta entre candidato e eleitores. Em cerca de 80 discursos, Vargas apresentou um projeto político nacional, entremeado por assuntos de interesse local, valorizando a participação de cada Estado no crescimento da Federação como um todo. O sucesso no pleito presidencial de 1950 foi em parte conseqüência de um cuidadoso trabalho de construção de sua imagem, realizado por Vargas desde seu primeiro mandato. Apesar de alguns autores concordarem que o marketing político surgiu no Brasil em 1954, na campanha de 1950 Vargas utilizou procedimentos sistemáticos de comunicação e propaganda eleitoral. Ações direcionadas a um público-alvo e uso inteligente dos meios de comunicação são técnicas da estratégia varguista e também do que hoje chamamos de marketing político.

\section{Palavras-chave}

Getúlio Vargas; eleições presidenciais; propaganda política 


\section{Abstract}

Regal, Débora Kfuri; Reznik, Luís. Back in the presidency: Getulio Vargas's strategy of propaganda in the 1950 elections. Rio de Janeiro: 2007. 115 p. MSc.Dissertation - Departamento de História, Pontifícia Universidade Católica do Rio de Janeiro.

This research is about Getulio Vargas' presidential elections campaign, in 1950. Vargas, who had reached presidency twice through coups and once through indirect elections, became once again president in 1950, due to an intelligent and modern campaign. During a couple of months, his entourage visited more than 50 cities and the Federal District, establishing a channel for direct communication between the candidate and the electors. In a series of speeches, Vargas presented his national political project, merged with local affairs, detaching the participation of each unit in the growth of the whole federation. The success in the presidential elections of 1950 was a consequence of a careful work of image construction, since Vargas' first mandate. Some authors argue that political marketing was not used in Brazil until 1954, but the claim of this work is that Vargas made use of systematic procedures of electoral propaganda and communication as early as his 1950's campaign. Focusedtarget actions and intelligent use of midia were part of Vargas' campaign and are also part of what we today know as political marketing.

\section{Keywords}

Getulio Vargas, presidential elections, political advertisement 


\section{Sumário}

$\begin{array}{ll}\text { 1. Introdução } & 10\end{array}$

2. A propaganda estatal no mundo da política 16

2.1 - Falando às massas: Lênin, Mussolini, Hitler, Roosevelt e Vargas 20

2.1.1 - Lênin: a política se espalha pelas ruas 20

2.1.2 - Mussolini: o líder onipresente 22

2.1.3 - Hitler: comunhão entre ideologia e método 23

2.1.4 - Roosevelt: uma experiência democrática 26

2.1.5 - Vargas: o presidente, os trabalhadores e a propaganda 29

2.2 - Comunicação getulista: as agências de propaganda do primeiro $\begin{array}{ll}\text { governo Vargas } & 31\end{array}$

2. 3 - A propaganda getulista em movimento permanente: marketing? 37

3. O período entrevargas e a campanha presidencial de 1950

3.1 - O segundo queremismo 48

3.2 - A preparação da campanha $\quad 55$

3.2.1 - Ou se faz uma campanha organizada ou é melhor desistir $\quad 59$

3. 3 - Rumo ao Catete 65

3. 4 - A campanha na estrada: revisitando o passado, projetando o futuro 67

4. Conclusão 101

$\begin{array}{ll}\text { Referências Bibliográficas } & 107\end{array}$

$\begin{array}{ll}\text { Anexos } & 111\end{array}$ 